Sergio Picciarelli Junior

As relações de comunicação no processo de produção na Gráfica Abril: inovações, criatividade e reconhecimento do uso de si na atividade de comunicação e de trabalho 


\section{As relações de comunicação no processo de produção na Gráfica Abril: inovações, criatividade e reconhecimento do uso de si na atividade de comunicação e de trabalho}

Dissertação apresentada ao Programa de PósGraduação em Ciências da Comunicação, Área de Concentração Teoria e Pesquisa em Comunicação, Linha de Pesquisa Epistemologia, Teoria e Metodologia da Comunicação, da Escola de Comunicações e Artes da Universidade de São Paulo, como exigência parcial para obtenção do Título de Mestre em Ciências da Comunicação, sob a orientação da Profa ${ }^{\text {. Dra }}$. Roseli Fígaro. 
Autorizo a reprodução e divulgação total ou parcial deste trabalho por qualquer meio convencional ou eletrônico para fins de estudo e pesquisa, desde que citada à fonte.

\section{Picciarelli, Sergio}

As relações de comunicação no processo de produção na Gráfica Abril: inovações, criatividade e reconhecimento do uso de si na atividade de comunicação e de trabalho / Sergio Picciarelli. - São Paulo : S. Picciarelli.

$250 \mathrm{f}$.

Dissertação (Mestrado) - Departamento de Comunicação e Artes / Escola de Comunicação e Artes / USP, 01/08/2009.

Orientador: Prof. Dra. Roseli Fígaro.

Bibliografia

1. Comunicação 2. Linguagem 3. Trabalho Gráfico 4. Encartes Especiais 5. Criatividade I FÍGARO. Roseli. II Título 


\section{Banca Examinadora}

Prof.(a) Dr.(a)

Instituição

Assinatura

Presidente

Prof.(a) Dr.(a)

Instituição

Assinatura

$1^{\circ}$ examinador

Prof.(a) Dr.(a)

Instituição

Assinatura

$2^{\circ}$ examinador

Aprovado em: 
"O esforço é para que os olhos vejam sem ilusão, e para que o ponto de vista não ofusque a visão" Roseli Fígaro

À Elisabet Rikli, que esteve comigo em mais esta etapa, me apoiando e incentivando nas horas difíceis. 


\section{Agradecimentos,}

À Prof. Dra Roseli Fígaro, minha orientadora e amiga, pela sua dedicação, carinho e atenção durante essa árdua jornada.

À Prof. Dra Cristina Costa, responsável por abrir novos horizontes na minha carreira o que me inspirou e impulsionou à outras buscas.

Parto mais confiante e experiente para a vida com este bem imensurável que é o conhecimento. Meus sinceros e eternos votos de gratidão a essas duas gigantescas educadoras que acreditaram e apostaram no meu trabalho.

À Prof. Dra Maria Irene pela gentileza de aceitar o convite para participar da minha banca de qualificação e pelas contribuições.

À equipe do grupo de pesquisa Comunicação e Trabalho. À Edilma Rodrigues, Ligia Ungaretti, Juliane Cavalcanti e ao Mestre Marcello Magalhães. Principalmente à Adaci Rosa, Janaina Visibeli e ao Wilian de Andrade pelas preciosas dicas. Especialmente à Claudia Nonato que me ajudou muito em diversas etapas.

Aos Professores Marco Antonio Almeida e Giulia Crippa, pela magnífica aula com um toque de bom humor.

Ao Carlos Orlando, profissional que acredita na educação e viabiliza não apenas projetos gráficos diferenciados mas também pesquisas acadêmicas e sonhos.

Ao Gustavo de Araújo, Elenilson Santos e Tiago dos Santos, uma grande equipe. Trazem a emoção e o orgulho estampado no rosto ao falarem sobre as suas experiências e conhecimento. Trocam o seu suor e a sua força de trabalho em prol dos objetivos da empresa.

Ao Antonio Quarelo, profissional despojado, responsável e audacioso, a carreira é marcada por um trabalho focado na superação e na solução para os desafios do dia a dia.

Ao Wellington Gomes, profissional curioso e inovador. Como professor de artes gráficas tem muito a ensinar para os seus alunos.

Ao Wilian de Souza, profissional competente e seguro, possui grande capacidade de criar e compartilhar o seu conhecimento com toda à equipe.

Ao Israel Bueno, sempre disposto a colaborar. Suas informações foram valiosas. Sua entrevista tornou-se um dos pilares do capítulo das análises.

Seria injusto esquecer dos bastidores, agradeço ao Silvio Tassinari, Eduardo Costa e Sergio Felix por autorizarem e confiarem na minha pesquisa.

Ao meu irmão, o meu parceiro das grandes conquistas.

Ao meu pai e à minha mãe que sempre batalharam pela minha educação. Lembrarei sempre das suas longas noites de trabalho, durante 10 anos, para proporcionar a nossa família melhores condições de vida.

Pai e Mãe, o resultado está aqui. 


\section{Resumo}

PICCIARELLI, S. As relações de comunicação no processo de produção da Gráfica Abril: inovações, criatividade e reconhecimento do uso de si na atividade de comunicação e de trabalho. 2009. 250 f. Dissertação (Mestrado) - Escola de Comunicação e Artes, Universidade de São Paulo, 2009.

O avanço das novas tecnologias, a informatização e a globalização vem alterando continuamente o perfil do trabalhador, as políticas de trabalho, os processos de produção e consequentemente as relações entre os indivíduos na sociedade. $\mathrm{O}$ ambiente de trabalho é campo privilegiado de discurso, formação ideológica, de desenvolvimento humano e influencia o andamento do cotidiano das demais instituições sociais. Nesse contexto a comunicação no mundo do trabalho deixa de ser tratada apenas como um sistema de informação e passa a fazer parte do acúmulo de capital. O objetivo dessa dissertação é demonstrar como a comunicação tornou-se base de organização dos processos de produção e como as relações de comunicação no nível da produção revelam o saber do trabalhador.

Palavras-chave: comunicação, linguagem, trabalho gráfico, encartes especiais, criatividade. 


\section{Abstract}

PICCIARELLI, S. As relações de comunicação no processo de produção da Gráfica Abril: inovações, criatividade e reconhecimento do uso de si na atividade de comunicação e de trabalho. 2009. 250 f. Dissertação (Mestrado) - Escola de Comunicação e Artes, Universidade de São Paulo, 2009.

The advancement of new technology, computerization and globalization is changing continuously the profile of the worker, policy work, working processes and consequently the relationship between individuals in society. The work environment is ideal forum for speech, ideological training, human development and the progress of the daily influences of other social institutions. In this context the communication in the world of work no longer be treated only as an information system and becomes part of the accumulation of capital. The objective of this dissertation is to show how communication has become the basis for organization of production processes and relations of communication at the show the production of knowledge worker.

Words-Key : communication, language, graphics work, especial inserts, creativity. 


\section{Sumário}

INTRODUÇÃO

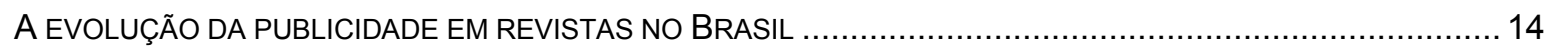

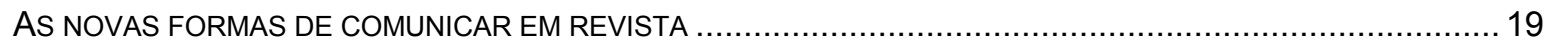

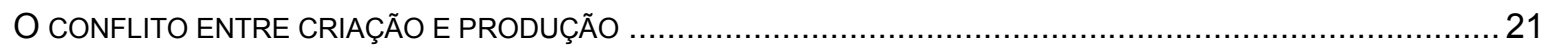

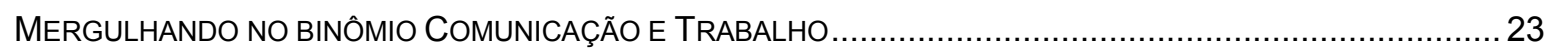

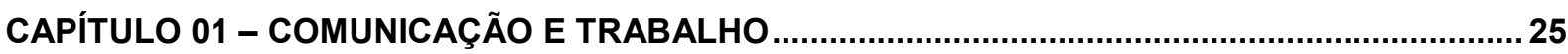

A LINGUAGEM E O TRABALHO

ERROR! BOOKMARK NOT DEFINED.

O ATUAL MODELO PRODUTIVO E A COMUNICAÇÃO. ERROR! BOOKMARK NOT DEFINED.

Um novo modelo produtivo - A New Economy.

Error! Bookmark not defined.

O COTIDIANO E O MUNDO DO TRABALHO. ERROR! BOOKMARK NOT DEFINED.

A infidelidade do meio

Error! Bookmark not defined.

ATIVIDADE DE TRABALHO E A COMUNICAÇÃO

ERROR! BOOKMARK NOT DEFINED.

A COMUNICAÇÃO, O TRABALHO E A CRIATIVIDADE

ERROR! BOOKMARK NOT DEFINED.

CAPÍTULO 02 - CONSTRUÇÃO DO OBJETO EMPÍRICO .......ERROR! BOOKMARK NOT DEFINED.

FORMULAÇÃO DO OBJETO DE PESQUISA.

ERROR! BOOKMARK NOT DEFINED.

A INSTITUIÇÃO PESQUISADA

ERROR! BOOKMARK NOT DEFINED.

A Gráfica Abril.....

Error! Bookmark not defined.

A Gráfica Abril em números

Error! Bookmark not defined.

Canais internos de comunicação da Gráfica Abril

Error! Bookmark not defined.

O Processo de Produção de Revistas

Error! Bookmark not defined.

A relação do pesquisador com a instituição

Error! Bookmark not defined.

O papel do pesquisador.

Error! Bookmark not defined.

TÉCNICA DE COLETA DE DADOS E CRITÉRIOS DE SELEÇÃO.

ERROR! BOOKMARK NOT DEFINED.

CAPÍTULO 3 - DESCOBRINDO O SABER DO TRABALHO ...ERROR! BOOKMARK NOT DEFINED.

A ATIVIDADE DE COMUNICAÇÃO E DE TRABALHO TRANSFORMAM O HOMEM . ERROR! BOOKMARK NOT DEFINED.

O CASO SHIEE - SISTEMA HÍBRIDO PARA IMPRESSÃO DE EFEITOS ESPECIAIS...... ERROR! BOOKMARK NOT DEFINED.

O TRABALHO INVISÍVEL, A CRIATIVIDADE E A COMPETÊNCIA

ERROR! BOOKMARK NOT DEFINED.

A APRENDIZAGEM NO TRABALHO POR MEIO DA LINGUAGEM

ERROR! BOOKMARK NOT DEFINED.

O CASO ENCARTE BANCO DO NORDESTE. ERROR! BOOKMARK NOT DEFINED.

O OPERADOR CRIATIVO VERSUS O PUBLICITÁRIO CRIATIVO

ERROR! BOOKMARK NOT DEFINED.

A MELHORIA DO PROCESSO PRODUTIVO POR MEIO DA COMUNICAÇÃO E DAS IDEIAS DOS OPERADORES

ERROR! BOOKMARK NOT DEFINED.

As entidades coletivas relativamente pertinentes

Error! Bookmark not defined. 
As relações no mundo do trabalho através das novas sociabilidades. Error! Bookmark not defined.

O Programa Contribua - um modelo comunicacional Error! Bookmark not defined. CONCLUSÃO .ERROR! BOOKMARK NOT DEFINED.

BIBLIOGRAFIA ...ERROR! BOOKMARK NOT DEFINED.

ANEXOS .ERROR! BOOKMARK NOT DEFINED.

COM AMOR DE OBSTETRA ERROR! BOOKMARK NOT DEFINED.

GRÁFICA SE DESTACA NO GOLDEN CYLINDER AWARD ERROR! BOOKMARK NOT DEFINED.

QUADRO 8 PÁGINAS ERROR! BOOKMARK NOT DEFINED.

Comunicado sobre qualidade. Error! Bookmark not defined. Comunicado sobre a política de reconhecimento - segurança e trabalho. ...Error! Bookmark not defined.

Comunicado sobre o programa Contribua. Error! Bookmark not defined.

Comunicado sobre o churrasco: Error! Bookmark not defined.

ENTREVISTA COM O AUXILIAR DE ACABAMENTO. ERROR! BOOKMARK NOT DEFINED.

ENTREVISTA COM O OPERADOR 3 DE ACABAMENTO. ERROR! BOOKMARK NOT DEFINED.

ENTREVISTA COM O GERENTE DE TECNOLOGIA E QUALIDADE ERROR! BOOKMARK NOT DEFINED.

ENTREVISTA COM O OPERADOR DE ACABAMENTO 2. ERROR! BOOKMARK NOT DEFINED.

ENTREVISTA COM O ESPECIALISTA GRÁFICO ERROR! BOOKMARK NOT DEFINED.

ENTREVISTA COM O TÉCNICO GRÁFICO 3. ERROR! BOOKMARK NOT DEFINED.

ENTREVISTA COM O OPERADOR DE IMPRESSÃO 2 ERROR! BOOKMARK NOT DEFINED. 


\section{Introdução}

A pesquisa tem por objetivo demonstrar como a atividade de comunicação e trabalho atua na renormalização (criação) dos processos de trabalho; como afeta a rotina, as tarefas e as habilidades dos profissionais de produção gráfica. Outra questão abordada pela pesquisa é a demonstração de como as relações de comunicação regem o processo produtivo, organizando-o e trazendo soluções e melhorias, tanto para a segurança dos operários como no consequente aumento do acúmulo de capital.

A comunicação pode nos ajudar a entender melhor os desafios e conflitos no mundo do trabalho, assim como a melhorar a qualidade do desempenho profissional, além de aproximar as áreas de criação e de produção gráficas. $O$ profissional criativo que fica atrás do computador, muitas vezes, desconhece os recursos disponíveis para viabilizar suas criações e não faz a menor ideia do conhecimento e da criatividade que o operador de uma máquina gráfica possui. A máquina só armazena o conhecimento passível de automação. Já o operador utiliza seu conhecimento pessoal, muitas vezes não-letrado, para viabilizar a produção dos projetos especiais através de macetes/inovações, de técnicas e de ideias tão criativas quanto as da equipe de criação da agência de publicidade.

O objeto foi estudado no campo acadêmico da comunicação. Lopes ${ }^{1}$ define o campo acadêmico da comunicação como um conjunto de instituições de nível superior destinado ao estudo e ao ensino da comunicação no qual se produz a teoria, a pesquisa e a formação universitária das profissões de comunicação com os seguintes sub-campos: científico, educativo e profissional. Esta dissertação se insere no campo da comunicação ao tomar como objeto de estudo as relações de comunicação que se dão no processo de trabalho em uma grande empresa gráfica e 
editorial, cuja, finalidade é a de buscar entender como a atividade de trabalho liga-se a atividade de comunicação no mundo do trabalho e como a política de comunicação da organização empresarial atua na organização da produção.

Para cumprir os objetivos desta dissertação, partimos da análise da produção gráfica da Editora Abril. A razão da escolha da empresa se deve à sua relevância na área de comunicação e cultura, e também ao fato de possuir o maior parque gráfico da América Latina. Por meio de alguns casos específicos, entrevistas e observações, buscamos identificar como as relações de comunicação ajudam a melhorar os processos produtivos e a revelar o conhecimento oculto do trabalhador.

\section{Da experiência de Gestão da Comunicação ao Mundo do Trabalho}

$\mathrm{Na}$ contemporaneidade, a relação entre tempo/espaço, sociedade e trabalho sofreram grandes transformações. A integração destas mudanças foi acompanhada por novos processos de homologação dos modelos de consumo. Hoje, as empresas não buscam apenas reforçar a presença da marca junto ao consumidor, mas também promover a interação do consumidor com a marca. Os profissionais de publicidade buscam novas formas de comunicar, de maneira a reforçar sua mensagem. No caso da mídia impressa, uma das opções é criar peças publicitárias com efeitos especiais, buscando aumentar a interatividade com o leitor. O objetivo destes recursos é alcançar os sentidos do leitor, utilizando diversas maneiras de comunicação não-verbal para traduzir, informar e comunicar. Estes projetos diferenciados por vezes implicam na necessidade de mudanças na linha de produção gráfica, exigindo alto grau de conhecimento técnico dos operadores de máquina e a utilização de equipamentos modernos.

Em 2006, realizei dentro da Editora Abril uma pesquisa sobre a criação e produção destes encartes. Os resultados estão na monografia "Encartes Especiais: A gestão do conflito entre publicidade e produção gráfica na mídia impressa da Editora Abril”, requisito final do Curso de Pós-Graduação lato sensu em Gestão da

\footnotetext{
${ }^{1}$ LOPES, Maria Immacolata V. Pesquisa em Comunicação. $7^{\text {a }}$ edição. São Paulo: Loyola, 2003.
} 
Comunicação da ECA-USP. O curso, que resultou na monografia, tem como um dos objetivos preparar profissionais de todas as áreas para conduzir a comunicação de forma eficaz e responsável, levando em conta as novas tecnologias de produção e comunicação, com o intuito de alcançar melhores resultados nas relações políticas, comerciais, científicas, acadêmicas, culturais e sociais. Chamou minha atenção a visão inovadora da proposta de formação especializada em gestão de comunicação, atribuindo ao profissional o papel de mediador da comunicação.

Virgílio Noya Pinto ${ }^{2}$ afirma que o grande desafio atual é preparar homens capazes de interagir não somente dentro de sua profissão, mas também perante um cenário de constantes mudanças e inovações. Nesse contexto, a formação do gestor deve compreender fortes referenciais humanísticos e apurada sensibilidade estética e social, a fim de privilegiar, nos processos comunicacionais, a interatividade, preocupando-se especialmente com a receptividade da mensagem.

Para Soares ${ }^{3}$, este novo profissional deve estar preparado para atuar em todas as atividades humanas em que se faz necessária a utilização dos recursos da comunicação e das artes para livre expressão do pensamento e da criatividade. A nova demanda social guiada pela função mediadora da comunicação exige um profissional capaz de identificar, planejar e avaliar de forma abrangente os processos de trocas de informações.

A pesquisa que realizei demonstrou os entraves e a clara oposição de interesses existentes entre as áreas de criação e de produção gráfica. A hipótese primária da pesquisa levou em conta a existência de uma barreira, junto à equipe da gráfica, em se trabalhar com o encarte diferenciado. Uma vez que a produção da gráfica é medida por desempenho e velocidade, é natural que a inserção de encartes especiais não seja vista de forma positiva, pois eles ocasionam quedas de velocidade na produção, desperdícios adicionais e paradas de máquinas. Por outro lado, em busca de maior faturamento, a empresa é obrigada a atender esta demanda e a oferecer processos especiais para o mercado publicitário. A partir

\footnotetext{
${ }^{2}$ PINTO, Virgílio Noya. Por um novo Profissional. In: BACCEGA, Maria Aparecida (org.). Comunicação e cultura: um novo profissional. 2.edição. São Paulo: CCA/ECA/USP, 2000. p. 7-9.

${ }^{3}$ SOARES, Ismar de Oliveira. Analista e Gestor de Processos Comunicacionais. In: BACCEGA, Maria Aparecida (org.). Comunicação e cultura: um novo profissional. 2.ed. São Paulo: CCA/ECA/USP, 2000. p. 23-29.
} 
desta problemática, ou seja, como os encartes especiais de publicidade mantêm-se competitivos em relação a outras mídias, realizei a minha primeira pesquisa.

No processo de estudo que desenvolvi, pude recuperar informações históricas que apontam a preocupação, já no início do século $X X$, da produção de anúncios publicitários mais criativos.

\section{A evolução da publicidade em revistas no Brasil}

Em 1808, a impressa régia chega ao Brasil com a vinda de D. João VI. Surge o primeiro jornal impresso no Brasil, Gazeta do Rio de Janeiro. Na mesma época, começam a surgir também os primeiros anúncios classificados: textos sobre a venda de propriedades, terrenos, escravos e outros. Em 1900, é lançada a primeira revista brasileira: Revista da Semana. No período, os anúncios já eram separados estrategicamente por temas e eram os responsáveis pela viabilidade financeira da produção das publicações.

Temos registros de anúncios interativos a partir do início do século $\mathrm{XX}$. Em 1908, a loja de chapéus Casa da Mangueira utilizou um anúncio que trazia, de um lado, a ilustração de um homem de perfil, sem chapéu - e, do outro lado, a imagem de um chapéu. O anúncio convidava o leitor a encostar o nariz no papel para que o chapéu parecesse se encaixar sobre a cabeça do homem ${ }^{4}$.

${ }^{4}$ MATUCK, M.A.S. O convite a interatividad Marketing, São Paulo:
1 Maria A.S. Matuck

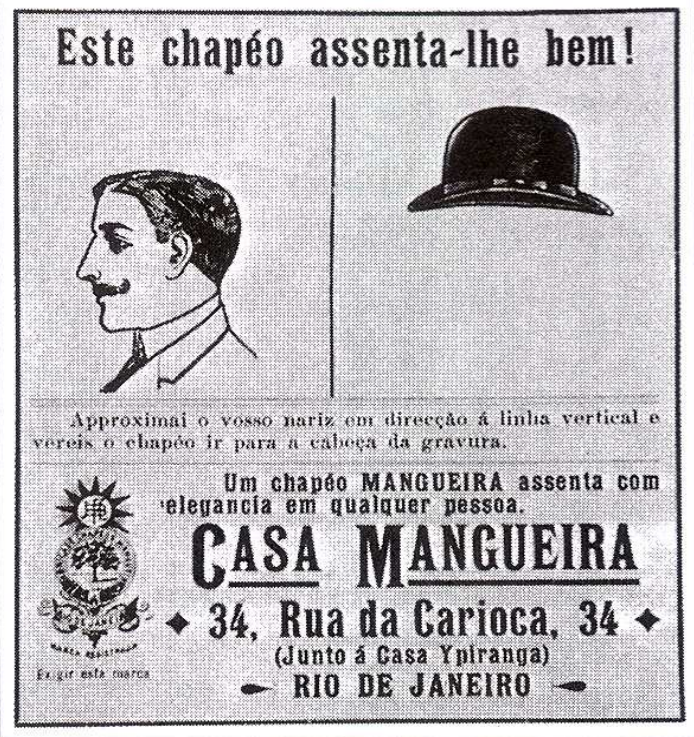

os nas peças publicitárias - um 1 - Escola Superior de Propaganda e 
No início do século $X X$, as gráficas adquirem novos equipamentos, propiciando aos almanaques e aos semanários trazerem imagens coloridas e anúncios de página inteira. Por volta de 1930, a revista Cruzeiro já vendia 700 mil exemplares por mês, trazendo textos e ilustrações coloridas.

O hábito e o comprometimento de as pessoas comprarem e colecionarem revistas abriu um importante espaço para a publicidade.

"O surgimento das revistas ampliou o espaço dos anunciantes e introduziu uma nova categoria profissional, o agenciador de anúncios, que era o intermediário entre os anunciantes e os veículos"

O sucesso das publicações e o consumo de bens duráveis e não duráveis em massa possibilitaram novos investimentos, novos lançamentos e o surgimento de novas editoras e agências de propaganda.

Em 1950, é fundada, pelo jornalista e empresário Victor Civita, a Editora Abril. Instalada em um pequeno escritório no centro de São Paulo, a empresa iniciou suas atividades com a publicação da revista infantil Pato Donald. No final daquela década, a Abril passaria por uma grande transformação, investindo em treinamento e tecnologia e atraindo profissionais talentosos. Em 1960, Victor Civita passa a publicar obras em fascículos, que se tornam grande sucesso editorial. Em 1969, a empresa já conta com diversos lançamentos editoriais como as revistas Capricho, Noturno, Meu Bem e Mickey. As revistas, em relação ao jornal impresso, aumentam a possibilidade de anúncios mais elaborados e em quatro cores. Nesta mesma época, já existem mais de cem agências de publicidade em atividade no Brasil e a mídia impressa já se via obrigada a disputar o mercado publicitário com o rádio e com a TV.

\footnotetext{
${ }^{5}$ ABREU, Alzira Alves ; PAULA, Christiane Jalles de (org). Dicionário histórico biográfico da propaganda no Brasil. Rio de Janeiro: Editora FGV : ABP, 2007. p. 11.
} 
A partir da década de 1960, diversas revistas da Editora Abril começam a trazer encartes publicitários como alternativa para os anunciantes. Com o boom das telecomunicações nos anos de 1970, devido à política de incentivo do governo militar, as gráficas novamente investem em seus parques gráficos, possibilitando melhorias na qualidade das imagens impressas. Era preciso inovar pois a TV já detinha $43 \%$ da verba publicitária, seguida pelas revistas com $22 \%$, o rádio com $15 \%$ e os jornais com $14,5 \%{ }^{6}$.

$\mathrm{Na}$ década de 1980, surgem os primeiros computadores destinados à indústria gráfica. $\mathrm{O}$ alto custo desses equipamentos, porém, faz com que grande parte do trabalho de montagem de páginas e retoque de cores ainda seja feito à mão. Nesta época, a Editora Abril possuía apenas quatro computadores, com custo estimado de 600 mil dólares cada. Ao mesmo tempo, uma equipe de aproximadamente 600 pessoas se revezava em três turnos, ainda executando grande parte do trabalho.

Na década de 1990 chegam os primeiros computadores a um custo muito mais acessível: por volta de 10 mil dólares cada. Assim, diversas redações e agências passam a adotar, em seu dia-a-dia, a tecnologia digital para criar e montar páginas. Na publicidade, o computador e os programas gráficos recém-chegados ao Brasil eram utilizados na montagem e retoque de fotos, assim como na criação de textos com efeitos de sombras, degradês e tipologias inéditas.

A partir desse momento, as transformações econômicas e políticas do mundo permitem parcerias entre agências brasileiras e agências internacionais. O Brasil fixa-se como potência publicitária mundial, aparecendo nos rankings da mídia especializada.

Os encartes e anúncios, porém, ainda se limitavam a páginas sequenciais sem efeitos especiais. A diferenciação estava no formato que ocupavam dentro das

\footnotetext{
${ }^{6}$ ABREU, Alzira Alves ; PAULA, Christiane Jalles de (org). Dicionário histórico biográfico da propaganda no Brasil. Rio de Janeiro: Editora FGV : ABP, 2007. p. 14.
} 
publicações: meias páginas, um terço de página, "ilhas"7 e outros. A interatividade, nessa época, é marcada apenas por textos, imagens e cupons para o leitor preencher e enviar pelo correio.

Em 1993, acontece a 40a edição do Festival de Publicidade de Cannes, premiação mais importante do mundo no setor. O Brasil conquista o primeiro Grand Prix na categoria Mídia Impressa, com um anúncio criado pela dupla Nizan Guanaes e Marcello Serpa, da agência DM9DDB, para o guaraná Diet Antarctica. Tratava-se de um anúncio de página dupla sem efeitos especiais. De um lado, trazia o corpo de uma mulher em ótima forma física; de outro, apenas a tampinha do produto sobre um fundo branco.

Em 1996, ocorre uma grande virada no mercado publicitário. As revistas passam a trazer anúncios com efeitos especiais, sofisticados. Começa a haver competição entre as agências, com o objetivo de superar sempre as criações publicitárias anteriores. Diversos prêmios de destaque são distribuídos entre as agências devido ao avanço na utilização de recursos especiais em publicidade.

Um dos destaques foi o encarte Audi, criado pela ALMAP/BBDO, para o modelo A8 da montadora de veículos, que ganhou o prêmio Leão de Ouro no Festival de Cannes, em 1996, pela criatividade e adequação à mídia. Impactante e surpreendente, foi veiculado nas revistas Quatro Rodas, Playboy, Vip e Caras em uma campanha de um milhão de dólares e que consumiu 160 quilômetros de Velcro $^{R}$. Leonardo Senna juntou formadores de opinião para que conhecessem a campanha e comprovassem em testes práticos que a aderência, bem anunciada, correspondia à verdade. Segundo Senna, o resultado foi ótimo, houve gente que comprou o carro na hora ${ }^{8}$. O encarte Audi A8 recebeu o prêmio por criatividade e adequação à mídia.

\footnotetext{
${ }^{7}$ Nome dado a espaços reservados para publicidade dentro das páginas redacionais.

${ }^{8}$ Para prender mais que a atenção. ed. 57, Boas Novas, São Paulo: out. 1996. p. 3.
} 

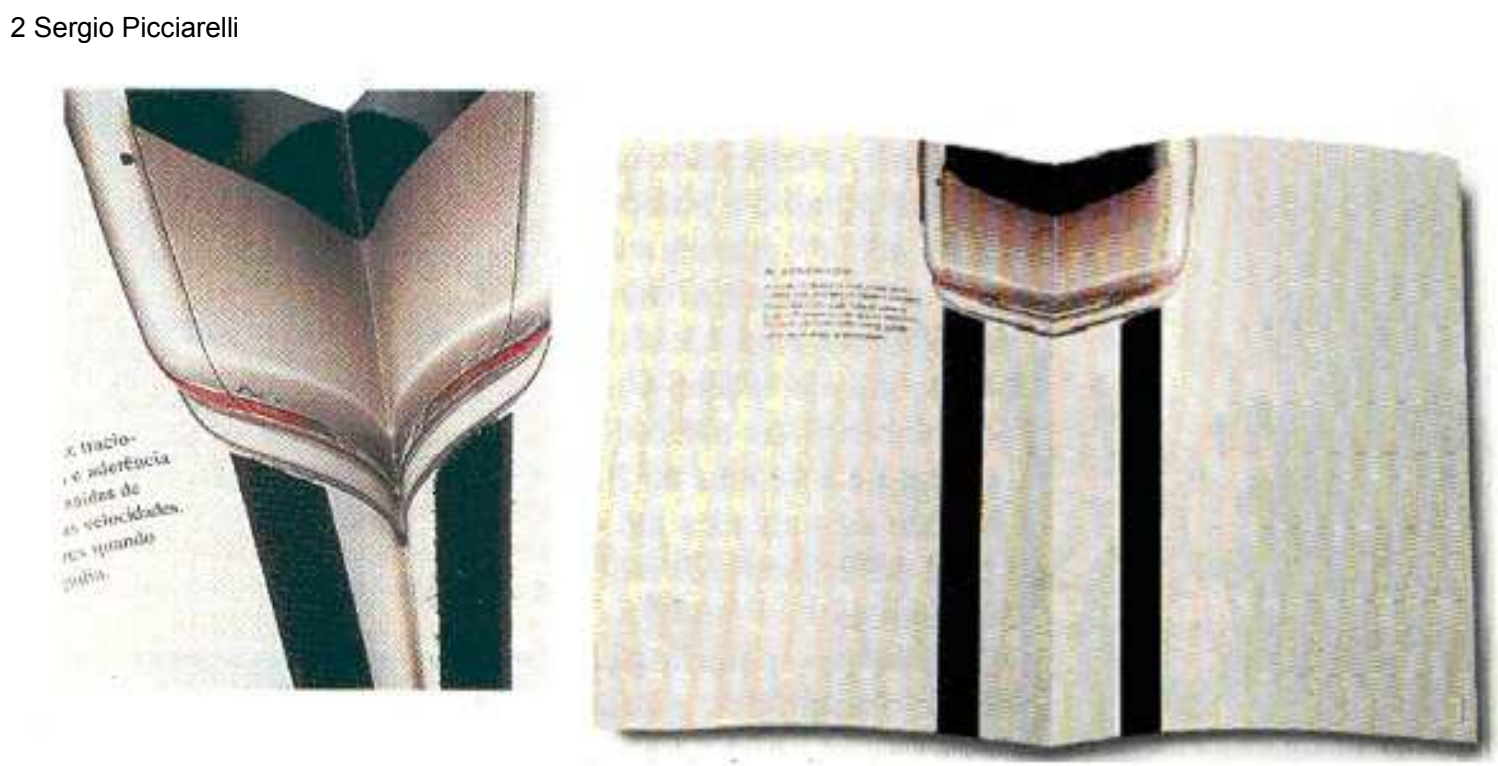

Nesta época, a Editora Abril e diversas gráficas se modernizam e investem em novos equipamentos, contratando e treinando novos profissionais. Em 1997, surge a área de Desenvolvimento de Novos Produtos (DNP), focada em viabilizar todos os projetos diferenciados criados pelas agências de publicidade. É considerado projeto especial todo anúncio veiculado na revista que não seja simplesmente uma página impressa. Normalmente estes projetos são veiculados em forma de encartes, utilizando recursos como pop-ups (anexos de papel que se abrem ao manusear a página), aromas, chips eletrônicos, cortes, vincos, serrilhas, colagens, personalizações, holografias, tintas e vernizes especiais.

Assim, desde a criação da tipografia por Johann Gutemberg, no século XV, que permitiu a reprodução editorial ilimitada - possibilitando o surgimento da figura do empresário e da tecnologia como bases do que veio a ser a indústria cultural até os dias de hoje, a mídia impressa firmou-se como importante meio de comunicação de massa. Por ser um meio de comunicação de massa concebido de forma a agradar o maior número de pessoas, a publicidade se utiliza dos anúncios em revistas para introduzir novos produtos e fornecer novas referências culturais. 
Procura estimular o desejo de consumo, modificar valores e influenciar no processo de percepção mental. Explora, por exemplo, o aroma cítrico como sinal de limpeza. O discurso publicitário muitas vezes busca influenciar o consumidor, empregando elementos verbais e não-verbais. Utiliza-se de diversos recursos na tentativa de homogeneizar o gosto do público e legitimar o consumo. Nossa realidade se torna cada vez mais mediada pelos meios de comunicação que, somados às novas tecnologias mudam a nossa relação com o mundo, em busca da interação e do estímulo dos nossos sentidos.

\section{As novas formas de comunicar em revista}

O maior domínio das técnicas e das tecnologias possibilitou ao profissional de comunicação abandonar procedimentos lineares em favor de múltiplos recursos comunicacionais. Esse fenômeno inclui a crescente importância do encarte especial na publicidade e na mídia impressa.

Atualmente as empresas buscam não apenas reforçar a presença da marca junto ao consumidor, mas também explorar de diversificadas maneiras a interação do consumidor com a marca. A comunicação verbal somada à não-verbal pode reforçar essa interação. Os efeitos aplicados nos encartes publicitários buscam o aumento da interatividade com o leitor. Procuram mexer com os seus sentidos, utilizando diversos recursos materiais e formas para a percepção e erigir expressões de comunicação não-verbal, com o objetivo de aproximar os leitores do produto e reforçar a comunicação verbal conceitual, traduzindo, informando e comunicando valores. Alguns encartes sugerem indução e comportamento, não se limitam apenas à leitura, mas aproximam o leitor do produto, quebram a racionalidade do texto e propõem-se a influenciar o comportamento dele, entrando em aspectos mais sensíveis e subjetivos que pegam o leitor desprevenido.

O entendimento do texto, segundo Costa $^{9}$, exige aprendizado e mecanismos de acessos aos seus segredos, já a linguagem visual se apresenta como igualitária, acessível, inclusiva, pois nossa capacidade de ver se desenvolve sem que tenhamos

\footnotetext{
${ }^{9}$ COSTA, Cristina. Educação, imagem e mídias. São Paulo: Cortez, 2005 p.45.
} 
que fazer grande esforço: "A experiência diária, o amadurecimento psíquico e o fortalecimento da identidade vão fazendo do olhar um mecanismo cada vez mais competente na relação que mantemos com o mundo".

Os encartes especiais trazem informações complementares ao signo verbal, como cor, textura e aroma. Dessa forma, o encarte pode ser composto por signos indiciais, criando evocações intensificadas pelo imaginário do leitor, e cuja capacidade de decodificação dependerá, entre outras coisas, do ambiente sóciocultural em que ele está inserido.

A linguagem verbal, base do pensamento conceitual, mobiliza e organiza os demais signos e ou efeitos contidos nos encartes para reforçar o entendimento das ideias que os autores desejam transmitir.

Além da motivação que o uso de diferentes linguagens e recursos de expressão provoca, o encarte frequentemente aborda signos privilegiados da cultura do público.

Uma das oportunidades de integrar a comunicação não-verbal com a comunicação verbal é o estímulo do olfato, cuja percepção é imediata e, em muitos casos, não pode ser traduzida pela comunicação verbal. A fragrância pode despertar diversas sensações, de forma mais rápida e intensa do que a imagem isolada. $O$ olfato humano pode identificar mais de cinco mil odores diferentes ${ }^{10}$. Já foram utilizadas em revistas desde fragrâncias de flores, passando por aromas que estimulam o apetite, como o de panettone, até os mais extravagantes, como aromas de uma fogueira ou de estábulo. É comum, em diversos encartes especiais, a utilização de etiquetas e vernizes com aromas de frutas, café, couro, perfumes, produtos de limpeza e outros, para aumentar o poder da mensagem.

\footnotetext{
${ }^{10}$ Estudo feito pela empresa alemã Follman \& CO que desenvolve e encapsula aromas para as revistas da Editora Abril.
} 
Para Moran ${ }^{11}$, é possível desenvolver formas sofisticadas de comunicação sensorial multidimensional, por meio da superposição de linguagens e mensagens que facilitam a aprendizagem e condicionam outras formas e espaços de comunicação. Os sentidos agem de forma complementar, como superposição de significantes, combinando e reforçando significados. O conhecimento visual facilita a compreensão do que não temos presente fisicamente, simulando a presença do que está longe. O conhecimento visual pode ilustrar e ajudar a compreender mais facilmente conceitos abstratos. O que não se vê perde existência. Um fato mostrado com imagem e palavra tem mais força que se somente mostrado com palavra. Muitas situações importantes do cotidiano perdem força, por não terem sido valorizadas pela imagem.

Outros encartes exploram a sensibilidade para sons, melodias e ambientes sonoros. A audição permite a comunicação sem o contato visual, reforçando também o reconhecimento simbólico.

Os profissionais das agências de publicidade buscam interagir com o leitor, intensificando o seu imaginário por meio de estímulos que integram diversas formas de percepção. Esta demanda altera os modelos de produção, exige um perfil diferenciado de profissionais envolvidos no processo e consequentemente traz alterações na organização e nas relações sociais no mundo do trabalho.

\section{O conflito entre criação e produção}

O estudo dos encartes publicitários especiais fez entender a relação intrínseca entre teoria e prática, ou seja, entre a descoberta de novas formas de comunicar e a necessidade cada vez maior de o mercado utilizar efeitos especiais para seduzir o leitor. Se por um lado tal relação desafia as agências de publicidade e a indústria gráfica a buscarem sempre novos processos, elas criam contradições que levam a insatisfação à produção gráfica em operar com esse tipo de publicidade, já que implicam em mudanças na linha de produção, quedas de velocidade e desperdícios adicionais no decorrer do processo.

\footnotetext{
${ }^{11}$ MORAN, Jose Manuel. Interferências dos meios de comunicação no nosso conhecimento. Revista INTERCOM - Revista Brasileira de Comunicação. São Paulo: Vol. XVII, n.2, Julho/Dezembro de 1994.
} 
É esse então um conflito para ser resolvido por meio da gestão da comunicação. Se por um lado, a área comercial deveria oferecer mais opções diferenciadas para os anunciantes com intuito de alavancar novos negócios; por outro lado, a produção é cobrada pela quantidade de exemplares produzidas/mês; é preciso produzir cada vez mais, além de tentar alcançar índices de desperdícios cada vez menores. Mesmo com todas as dificuldades, existia uma receptividade positiva por parte de algumas equipes à realização do encarte. Sílvio Tassinari, gerente de produção do acabamento da gráfica, comenta que muitos operadores de máquina encaram como desafio a produção de uma revista com encartes especiais, sentindo orgulho em fazê-los. Porém, ainda era necessário mostrar a toda a equipe a importância de incrementar a produção. ${ }^{12}$

Quase todos os trabalhadores da produção, incluindo supervisores, desconheciam a importância desses encartes para a receita do Grupo Abril. Existia, no entanto, receptividade para a realização de uma campanha interna de conscientização a respeito, especialmente, do sistema de cobrança dos encartes. Antonio Quarelo, analista de processo, concorda com Tassinari a respeito da visão favorável de alguns profissionais ao encarte, mas considera esse um fenômeno incipiente. Para a maioria dos profissionais do setor de gráfica, os encartes ainda são vistos como um complicador à produção.

Wesley Silva, operador de máquina, e Edmilson dos Santos, líder de máquinas, confirmaram o desconhecimento a respeito do sistema de preço diferenciado para os encartes especiais. Eles afirmaram que gostariam de tomar conhecimento do fluxo de informações, desde a entrada do projeto na área de publicidade até a área de faturamento, assim como dos benefícios que este tipo de projeto traz para a empresa.

Existe o desejo, por parte das equipes, de maior participação no processo de desenvolvimento dos encartes. O reconhecimento do anunciante é importante para estimular os operadores. De acordo com os entrevistados, o gerente da área

\footnotetext{
${ }^{12}$ Entrevista realizada no dia 01 de fevereiro de 2006.
} 
costuma parabenizar o resultado final do trabalho, mas não costuma destacar a importância do trabalho para a empresa de modo geral. Dessa forma, é necessário, ainda, fazer com que as equipes de produção se sintam parte do projeto de realização do anúncio, merecedores também do reconhecimento do cliente.

O resultado da pesquisa desenvolvida no primeiro semestre de 2006 para o curso Gestão da Comunicação demonstrou que havia a necessidade de se criar um projeto $^{13}$ de gestão de comunicação entre as áreas comerciais e de produção gráfica da empresa, com o objetivo de minimizar os conflitos gerados pelo aumento do número de encartes especiais, veiculados pelas agências, e a desinformação da área de produção quanto à perda de volume nas peças produzidas, que, ao contrário do senso comum da equipe, não acarreta perda de valores absolutos no faturamento da empresa.

\section{Mergulhando no binômio Comunicação e Trabalho}

Após a conclusão do curso de especialização Gestão da Comunicação, fui convidado a participar do Grupo de Pesquisa "Comunicação e Trabalho"14, da Escola de Comunicação e Artes, que é credenciado no CNPq e coordenado pela professora doutora Roseli Fígaro, desde sua criação em 2003.

As pesquisas realizadas com o grupo e o aprofundamento teórico me despertaram questões sobre o conhecimento oculto do trabalhador e a sua criatividade, a qual pode ser equiparada ao do profissional das agências de publicidade. Pude perceber também, sem a menor dúvida, que as relações de comunicação regem todo o processo produtivo, organizando-o, trazendo soluções e melhorias, para a segurança dos operários e consequentemente maior lucratividade para a empresa.

Esse aprendizado levou-me a aprofundar meus estudos, buscar maior aprofundamento teórico e a propor para esta dissertação duas questões:

\footnotetext{
${ }^{13}$ Para maiores detalhes a respeito das intervenções propostas consultar o relatório completo que foi depositado na biblioteca da Escola de Comunicação e Artes.
} 
- O operário gráfico desenvolve um trabalho tão criativo quanto o profissional de publicidade?

- As relações de comunicação no mundo do trabalho revelam o saber do trabalhador?

Tais questões podem ser especificadas com as seguintes perguntas:

- Um método de comunicação mais efetivo entre os profissionais envolvidos no processo de criação, administração e os profissionais de produção, pode melhorar os índices de produção?

- Os trabalhadores gráficos, mesmo novatos, assim como os de outras categorias, possuem conhecimentos pessoais sem os quais seria impossível a viabilização de projetos especiais?

- O conhecimento dos operadores pode ajudar a superar a infidelidade do meio?

- As prescrições são incapazes de abranger a totalidade das variáveis que surgem durante o trabalho?

Para respondê-las, estruturamos o trabalho em três capítulos. O capítulo 1 traz os conceitos teóricos que orientaram e estruturaram o pensamento científico na elaboração da pesquisa e na construção desta dissertação. No capítulo 2, apresentamos a construção do objeto empírico, a história da instituição pesquisada, seu modelo comunicacional e o processo de produção de uma revista. Neste capítulo propomos também a metodologia de pesquisa a partir da problematização do objeto de estudo, com as hipóteses que norteiam a pesquisa, os critérios de seleção e as técnicas de coleta de dados - observação, seleção e operacionalização. No capítulo 3 , analisamos o objeto à luz das teorias e dos dados

${ }^{14}$ Essas informações estão disponíveis no sítio: http: //www.eca.usp.br/comunicacaoetrabalho . Acesso em 12 de junho de 2009. 
coletados durante todo o curso de mestrado. São colocados os elementos constitutivos da investigação, assim como os resultados da pesquisa em campo. Foram analisados dois casos específicos; as contribuições dos trabalhadores para o processo; formas de expressar sua criatividade e a política de comunicação da empresa voltada para a produção. Descrevemos ainda as relações entre o objeto e o modelo teórico proposto, unificando teoria e prática.

\section{Capítulo 01 - Comunicação e Trabalho}

Neste capítulo, vamos mobilizar alguns conceitos das teorias da comunicação. Demonstrar como essas teorias se engajam no mundo do trabalho. Notaremos um movimento de intersecção e uma convergência entre saberes que dão origem ao binômio Comunicação e Trabalho. Este conceito, de comunicação no mundo do trabalho e a correlação entre atividade de comunicação e a atividade de trabalho norteiam a nossa pesquisa.

Este referencial teórico nos orientará nas tomadas de decisões, na elaboração da metodologia bem como nas condições de operacionalização da pesquisa em campo. Assegurará que a investigação seja enquadrada em conceitos teóricos e analisada de modo claro e defensável com base num campo científico. 
